\title{
CANE ADVISER: A MOBILE BASED APP FOR TRANSFER OF TECHNOLOGY IN SUGARCANE
}

\author{
T. Rajula Shanthy*, S. Alarmelu, C. Jayabose, P. Malathi and Bakshi Ram
}

\begin{abstract}
The information and communication support for sugarcane crop has been mainly conventional with limited personalized extension services to reach all the cane growers spread across the country. The diversity of agro ecological situations, varied technologies recommended and needs of sugarcane farmers further mount to this challenge. Information and Communication Technology and in particular mobile technologies are seen as a game changer in agriculture. It is commanding therefore for the sugarcane technology dissemination system operating across the states, to shift from being predominantly traditional, to harness the potentialities of information technology bridging the barriers of time and space. Keeping this in view, the ICAR-Sugarcane Breeding Institute of the Indian Council of Agricultural Research, has developed an interactive androidbased mobile app, Cane Adviser to serve to the needs of the stakeholders in sugarcane cultivation. The paper explains how Cane Adviser was developed methodically taking into account the information needs of the target audience, deciding the various modules to be embedded in the app and how it was evaluated before hosting in google play store. Explaining the various particulars of the mobile app, the paper details the role of Cane Adviser in disseminating sugarcane technologies and timely delivery of information tailor-made to the cane growers and cane development personnel so as to get enhanced cane productivity.
\end{abstract}

Keywords : Mobile app, Sugarcane, Transfer of technology, ICT modules, Digital communication

\section{Background}

The onset of green revolution in the mid-sixties in India led to a major technological breakthrough which could give a fresh impetus to agricultural productivity; more so in a long duration crop like sugarcane which remains in the field for at least 36 months as plant and ratoon crop. Though new sugarcane varieties and relevant crop management technologies are evolved, sugarcane productivity in the country hovers around $80 \mathrm{t} /$ ha. With no choice for horizontal expansion, the increasing demand for sugarcane as a raw material for myriad products has to be met only through vertical growth. Being a crop grown in over 5.2 million hectare area by nearly six million farmers (Bakshi Ram 2018), physical reach through the public extension service seems limited. It is in this context, that an efficient information dissemination system becomes inevitable. The increasing penetration of mobile phones and mobile enabled information services can reduce information asymmetry and complement the role of extension services in making useful information available to the sugarcane growers.

Mobile applications (M-apps) are software designed to take advantage of mobile technology and can be developed for transfer of technology in agriculture as well. Mobile phones have many key advantages like affordability, wide ownership, voice communications, and instant and convenient service delivery (Christine et al. 2011, Adongo et al. 2019). Most mobile apps on crops focus on

T. Rajula Shanthy, S. Alarmelu, C. Jayabose, P. Malathi and Bakshi Ram

ICAR-Sugarcane Breeding Institute, Coimbatore-641007, Tamil Nadu, India

*Corresponding author: rajula.sbi@gmail.com

Submitted: 27 December 2019; Accepted: 26 March 2020 
supply chain integration and have a wide range of functions, such as providing market information, increasing access to extension services, and facilitating market links. The diverse user-base includes farmers, produce buyers, cooperatives, input suppliers, content providers, and other stakeholders who demand useful, affordable services. But the potential development impact of such apps mainly lies in their ability to provide access to useful, relevant information and services.

Sugarcane is a major cash crop in India and the information and communication support for sugarcane crop has been mainly conventional with limited reach to the cane growers who are spread across the whole country. The diversity of agroecological situations in the sugarcane growing states, the varied technologies recommended and the needs of sugarcane farmers further mount to this challenge. Information and Communication Technology (ICT) and in particular mobile technologies are often seen as a game changer in agriculture (Mittal and Kumar 2000, Muto and Yamano, 2008). Hence, an attempt is being made to harness the potentialities of information technology through the development of a mobile app for technology dissemination bridging the barriers of time and space.

The app 'CaneAdviser' envisaged in this endeavour targets to provide growers and cane development personnel with timely access to extension services such as advancements in scientific sugarcane production, advice on appropriate technology and other related services.

\section{What is 'Cane Adviser'?}

Cane Adviser is a computer program designed to run on mobile devices such as smart phones and tablet computers and is accessible for anybody interested to know about scientific sugarcane cultivation.

\section{How 'Cane Adviser' was developed?}

\section{Requirement Analysis}

As a prelude to development of the mobile app, focus group discussions were conducted at farmer's level and cane development personnel to know the information needs of the intended users from the app. The requirement of sugarcane growers / cane development personnel was analyzed through focus group discussions conducted in the villages as well as during other interface meetings with farmers and cane staff. The information was collected in terms of the type of mobile phones used, pattern of mobile use, content needs in the app, services required through the app, format of the messages, preferred medium of communication etc. The information gathered was analyzed and accordingly the app was developed.

\section{Project Architecture}

The development process included conducting baseline survey, digitization of data, content management in terms of sugarcane varieties, production and protection technologies, developing the mobile app in android platform, provision for digital flow for sending messages, facilities for mobile transmission, pilot study, performance analysis and finalizing the module.

\section{Project Design}

The various stages involved in the project design are explained below:

- Project Architecture: The beginning of the development of any software involves meticulous planning of the basic structure and this was done in consultation with the technical experts considering the needs of the users.

- User Interface Design: The mobile app is designed in such a way that the user can interact with the software at every stage of entering i.e. from registration onwards. The interaction mode was made possible by 
navigation elements given through hyperlinks.

- Documentation: This app contains information from sett planting to harvesting, otherwise referred as technical part. The content involves mainly text and graphics in the form of still pictures and animation. The text runs to around 220 pages with more than 650 digital stills describing the content depicted.

- Database Architecture: A database on sugarcane farmers forms a part of this mission. A request was made to all the sugar factories to send details of the cane growers. Based on the response obtained from different states of the country, a database in MS excel with over 1.6 lakh records was created. This database is left open ended so as to leave room for updates and the database would serve as a base for the details on farmers including name, address and mobile number of the registered users.

\section{Development}

- Programming: The programming of the entire app was done using java script with $\mathrm{html}$ coding as the base.

- Integration: The integration of the various elements in the app like text, graphics, animation, hyperlinks was done in a way to have a smooth flow as expected in the design architecture.

- Code Review: After programming and rendering the integration of the various aspects of the app, the code review was done to test verify the linear flow of information. Testing and debugging was done at this stage to make the app error free.

- Configuration, Environment support: The app would fit in any android based smart phone irrespective of the configuration, which is a stand alone module. It has been made in a way that one-time internet connection alone is required for downloading the app. Further, query mode needs to be internet based so as to function on real time basis.

- Versioning: Right from rough cut, the module was created in a single version pattern with provision for further updates at any time.

- Backup and recovery set up: The entire content was put in a base module from which the navigation and hyperlinks had been created to make it into a single module.

\section{Testing}

- System test: This is a critical feature especially for the web based applications involved in this app. The basic requirements were worked out and made available before commencement.

- Performance test: The module was developed and tested in several platforms with varying technical configuration and was found to perform as expected.

- Content management and Data maintenance: This aspect is being done by the Server administrator and is more concerned with handling the queries from users. The user here has the option to send queries as live still photos or images from gallery or merely as a text matter. The admin sorts the queries, refers to experts concerned, if needed and the reply is sent as SMS or email.

- Hardware and server set up: The minimum requirement is a Server computer with $6^{\text {th }}$ Gen Intel Core i5 Processor i5-6400T (quad core) and IBM license WinSvrSTDcore 2016 SNGL OLP 2Lic NL Acdmc CoreLic and WinSvrCAL 2016 SNGL OLP NL Acdmc DvcCAL to be made functional for the web based applications.

- Application on live: The apk format of the module was initially made for testing the alignment and debugging. After testing and making necessary corrections, the final format was hosted in google playstore. 


\section{How to Access 'Cane Adviser'}

'Cane Adviser' is available in google play store, an international online software store for free download. This app would fit in any android based smart phone irrespective of the configuration, which is a stand-alone module. The entire matter was developed in English and then translated to Hindi and Tamil so as to have the app trilingual. The app is available as 'Cane Adviser' in English in accordance with ICAR norms and 'Ganna Salahkar' in Hindi and 'Karumbu Aalosakar' in Tamil.

\section{Modules in 'Cane Adviser'}

The features of the app developed include static as well as dynamic platforms embedded in the app. A few modules available in the mobile app are listed below:

\section{Login dialogue}

This go-ahead user-interface is the first step towards registration. Registration in the app is done by using mobile number authenticated by a one-time password. The particulars needed for registration include name, mobile number, address and email (optional).

\section{Splash Screen}

Splash Screen or Launch Screen is the opening window in an android app. It is implemented as an activity that gives the user an idea about the theme background and starts up any task. Once the app has bootstrapped, the splash screen starts the main activity leading to the menu page, where the various options are displayed and removes itself from the application back stack.

Depending on the choice of language, the splash screen appears as given below - 'Cane Adviser' in English, 'Ganna Salahkar' in Hindi and 'Karumbu Aalosakar' in Tamil. The splash screen, in turn leads to the menu page, where the various options are displayed (Fig. 1).

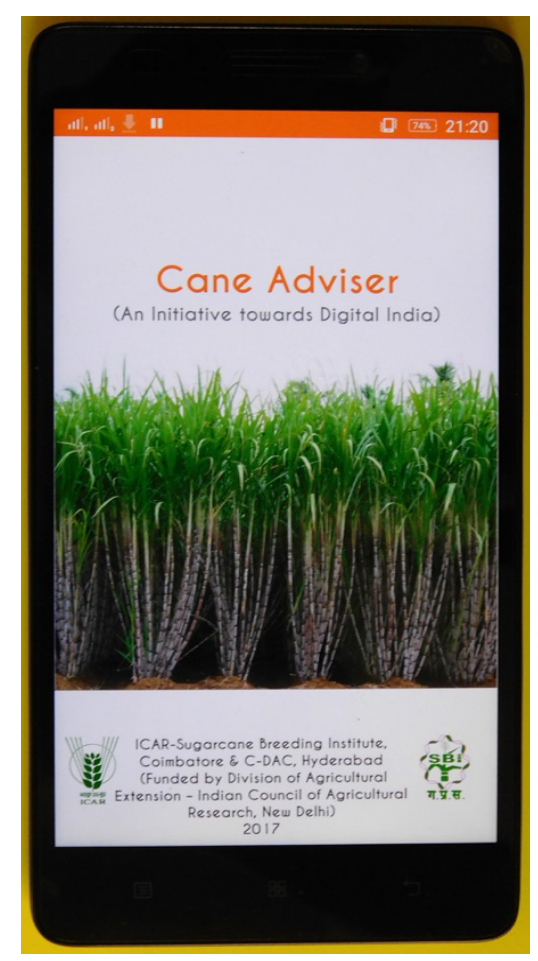

Fig. 1. Splash Screen

\section{Menu Screen}

The Menu Screen or the Home Page has the following options

1. Sugarcane Technologies

2. Scheduler

3. Query Handler

The scroll down button on the top left corner gives the list as:

1. Home

2. About Sugarcane Breeding Institute

3. Mandate

4. Contact Us

5. Credentials

6. Sugarcane Research Stations

7. Logout

\section{Knowledge Base}

This static downloadable display of knowledge base, contains information on sugarcane agriculture right from planting to harvesting, 
otherwise referred as technical part. The content involves mainly text and graphics in the form of still pictures. The information is given as statewise varieties, crop production technologies, pest identification and management, disease identification and management and ratoon management. The general contents include history of the institute, mandate, Sugarcane Research Stations etc.

\section{Fertilizer schedule}

Apart from the information on nutrient management detailed in the knowledge base, the app contains information on recommended dose of fertilizer for all the sugarcane growing states.

The unique features of Cane Adviser are Scheduler menu and Query Handler:

\section{Scheduler menu}

This is a unique feature of this mobile app. Ingrained in the module is a scheduler menu, which is tailor-made for each individual registered user. The basic inputs for registration include date of planting, choice of crop (plant / ratoon), state (tropical / sub-tropical) and option of season (autumn / spring). Corresponding to the date of planting, continued advice and reminder messages on the calendar of cultural operations to be carried out are popped up on real-time mode.

\section{Query handler}

As the eventual dialogue window, the user has the option to raise queries either as text messages or in graphic form, be it as live images or from the gallery. The queries are then replied by the administrator via message sorting, short message service, email etc.

\section{The Logic Flow}

The logic flow of information and functioning of Cane Adviser is described in fig.2.

\section{General Content}

The general content in the app includes

- History of ICAR-SBI - Contains a brief note on the important milestones of the institute since 1912.

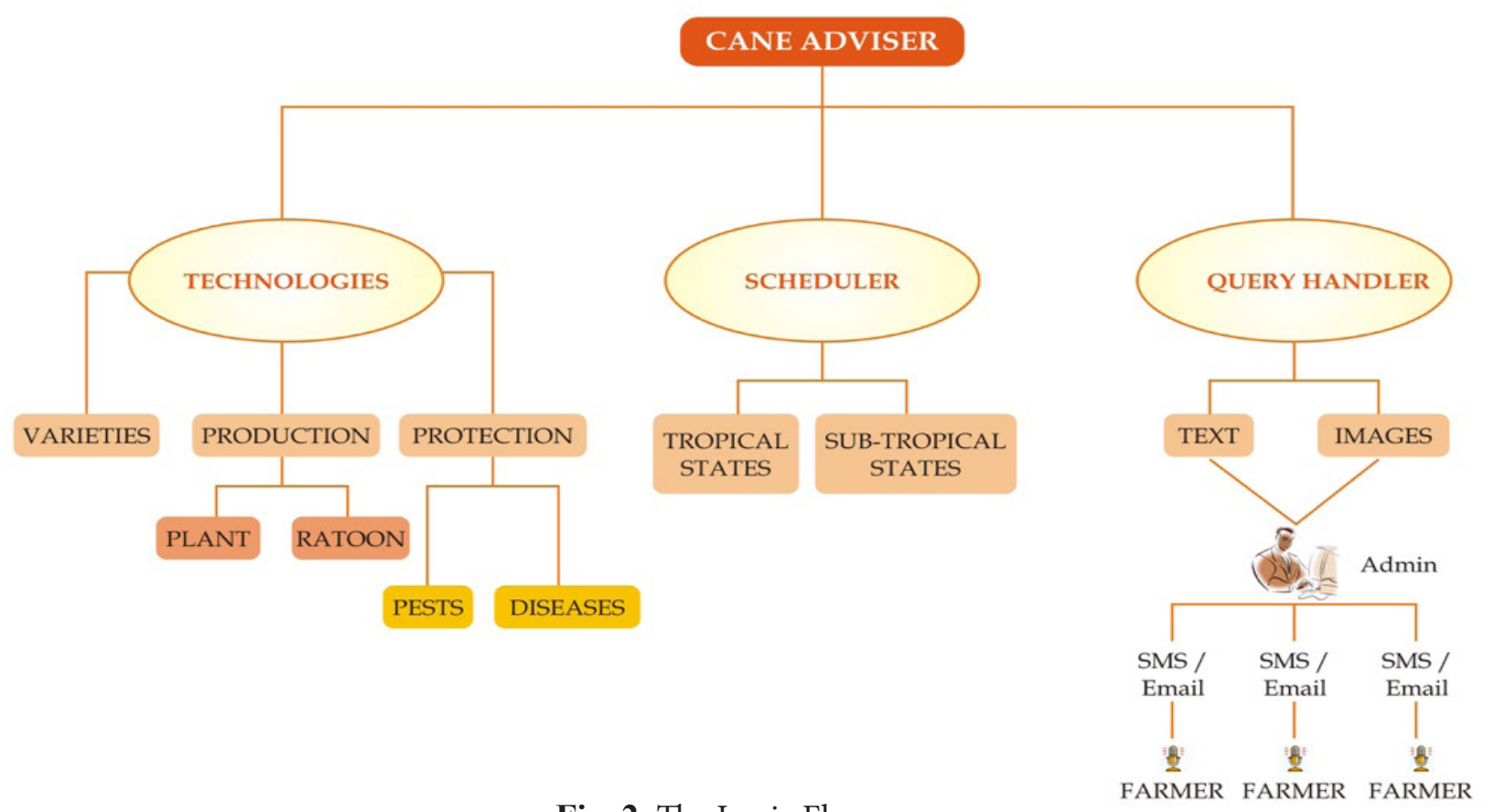

Fig. 2. The Logic Flow 
- Mandate - Gives details on the identified areas in which the institute focuses in research / extension and adoption.

- Contact us - Contains information for the users to get in touch with the institute

- Sugarcane Research Stations - This application provides state-wise name, address and contact details of Sugarcane Research Stations in the country in a scroll-down menu.

- Saccharum species - Gives details on the various species of sugarcane and other related genera with images

The major challenges in mobile advisory systems are its sustainability, delivering information on time, giving the right solution and winning the confidence of users. The app envisaged in this endeavour targets to provide farmers, cane staff and other users with timely access to extension services such as advancements on scientific sugarcane production, advice on appropriate technology, and other related services. Cane Adviser is a pioneering M-extension initiative by a research institute of the Indian Council of Agricultural Research. This android app has been listed in the Knowledge Initiatives section of ICAR website (https://icar.org.in/mobile-apps) and is highly rated by the users. With downloads from 59 countries, the number of hits so far are 135120. On an average, there are 25-30 queries per month from users through the Query Handler and its mainly on production technologies. The present app is available in three languages (English, Hindi and Tamil) and there is a demand for the app to be made in other languages as well.

Nevertheless, the mobile application developed would serve as a digital compendium of sugarcane related vocabulary comprising all details on sugarcane agriculture and can serve as a ready reckoner for sugarcane growers and cane development personnel working with sugarcane knowledge.

\section{Acknowledgements}

This mobile app is the result of a research project on 'Developing a mobile app on sugarcane: An initiative towards digital India' funded by Extramural Project, Division of Agricultural Extension, Indian Council of Agricultural Research, New Delhi. Technical assistance of C-DAC, Hyderabad is gratefully acknowledged.

\section{References}

Adongo JM, Wesonga PS, Serykhan NW (2019) The role played by mobile phone connection in the diffusion of dairy goats rearing in Kitui county, Kenya. Universal Journal of Agricultural Research 7(4):161-167.

Bakshi Ram (2018) Current status of sugarcane agriculture in major cane growing states in India. In: Rajula Shanthy $\mathrm{T}$ and Bakshi Ram (Eds.) Best management practices for sustained sugarcane productivity. ISBN 9789385267130. p.1-8.

Christine ZQ, Kuek SC, Dymond A, Esselaar S (2011) Mobile applications for agriculture and rural development. ITC Sector Unit, World Bank.

Mittal Surabhi, Kumar P (2000) Literacy, technology adoption, factor demand and productivity: An econometric analysis. Indian Journal of Agricultural Economics 55(3): 490-499.

Muto, Megumi, Yamano T (2008) The impact of mobile phone coverage expansion on market participation panel data evidence from Uganda, Draft Discussion Paper, Japan International Co-operation Agency (JICA). 